\title{
PEMAHAMAN MAHASISWA PG-PAUD SEMESTER III TERHADAP KEMAMPUAN MENGGUNAKAN APLIKASI BLANDED LEARNING DALAM PERKULIAHAN
}

\author{
Suharni $^{1}$, Sean Marta Efastri ${ }^{2}$, Azlin Atika Putri ${ }^{3}$ \\ Universitas Lancang Kuning \\ Email: suharni@unilak.ac.id ${ }^{1}$, Email: seanmarta@ unilak.ac.id ${ }^{2}$,Email: azlinpuput04@gmail.com \\ Suharni., Sean Marta Efastri, Azlin Atika Putri,. (2020). Pemahaman Mahasiswa PG-PAUD Semester VI \\ Terhadap Kemampuan Menggunakan Aplikasi Blanded Learning dalam Perkuliahan. \\ Jurnal Pelita PAUD, 4(2), 304-307. \\ doi: https://doi.org/10.33222/pelitapaud.v4i1.1016
}

Diterima:24-06-2020

Disetujui: 27-06-2020

Dipublikasikan: 30-06-2020

\begin{abstract}
Abstrak: Tujuan dari penelitian ini adalah untuk mengetahui pemahaman mahasiswa PGPAUD semester III dalam penggunaan aplikasi Blanded Learning. Penelitian deskriptif ini dilakukan dengan pemberian angket kepada mahasiswa sehingga peneliti mengetahui permasalahan dan kendala yang dihadapi oleh mahasiswa dalam penggunaan aplikasi Blanded Learning pada pembelajaran dimanapun mahasiswa berada. Diharapkan dengan penelitian ini dapat mengetahui pemahaman mahasiswa dalam menggunakan aplikasi Blanded Learning sebagai media pembelajaran. Hasil penelitian sementara menunjukkan bahwa pemahaman sebagian mahasiswa semester III terhadap kemampuan penggunaan aplikasi blanded learning rata-rata baik namun masih ada sebagian kecil yang mengalami kendala yaitu dalam menggunakan metode yang terdapat dalam aplikasi dan masih dibantu dalam mengakses fitur blanded learning sehingga mahasiswa harus tetap didampingi dan diarahkan dalam menggunakan aplikasi blanded learning. Dari hasil penelitian menunjukkan fitur blanded learning merupakan aplikasi yang efektif ketika tidak bertatap muka sehingga sangat membantu mahasiswa maupun dosen ketika tidak memungkinkan untuk melakukan pembelajaran dikelas.

Kata kunci: Pemahaman, media pembelajaran,blanded learning
\end{abstract}

Abstract: The purpose of this study was to determine the understanding of PG-PAUD semester III students in using the Blanded Learning application. This descriptive study was conducted by giving questionnaires to students so that researchers know the problems and obstacles faced by students in using the Blanded Learning application in learning wherever students are. It is expected that this research can find out student understanding in using the Blanded Learning application as a learning medium. The results of the interim study showed that the understanding of some of the third semester students of the ability to use blanded learning applications was on average good, but there were still a small number who experienced problems in using the methods contained in the application and were still assisted in accessing the blanded learning features so that students should still be accompanied and directed in using blanded learning applications. From the results of the study showed the blanded learning feature is an effective application when not face to face so it is very helpful for students and lecturers when it is not possible to do class learning.

Keywords: Understanding, learning media, blanded learning

http://jurnal.upmk.ac.id/index.php/pelitapaud 


\section{PENDAHULUAN}

Internet saat ini telah menjadi bagian yang tidak terpisahkan dari gaya hidup berbagai kelompok masyarakat Indonesia. Data hasil survei yang dilakukan oleh Asosiasi Penyelenggara Jaringan Internet Indonesia (APJII) pada tahun 2016 menunjukkan bahwa kalangan mahasiswa merupakan pengguna internet terbesar di Indonesia dengan 89,7\%, dan urutan kedua pelajar dengan 69,8\% namun akses terhadap laman pendidikan masih sangat kurang. Sebuah permasalahan yang perlu untuk disikapi oleh para pendidik dengan mengarahkan mahasiswa/peserta didik untuk lebih menggunakan internet dalam ranah pendidikan.

Salah satu fitur yang digunakan di FKIP Unilak adalah aplikasi blanded learning yang digunakan dalam perkuliahan. Pemahaman mahasiswa dalam menggunakan aplikasi blanded learning sangat penting karena jika mahasiswa tidak mampu mengoperasikan aplikasi blanded learning maka mahasiswa akan mengalami kesulitan bahkan tidak dapat mengikuti pembelajaran yang dilakukan melalui aplikasi blanded learning. Hal tersebut sangat merugikan mahasiswa karena ketika dosen melakukan pembelajaran dengan blanded learning maka mahasiswa yang tidak dapat memahami dalam menggunakan aplikasi blanded learning tidak dapat mengikuti pembelajaran tersebut sehingga mahasiswa ketinggalan dalam pembelajaran mengethaui sejauh mana pemahaman mahasiswa dalam menggunkan palikasi blanded learning dalam perkuliahan sehingga pendidik dapat mengevaluasi agar pembelajaran dengan menggunakan aplikasi blanded learning berjalan dengan lancar. Maka, mahasiswa harus memahami dalam mengoperasikan aplikasi blanded learning dan proses pembelajaran yang dilaksanakan berjalan lancar.

\section{METODE PENELITIAN}

Penelitian ini merupakan penelitian deskriptif dengan menggunakan pendekatan kualitatif.Penelitian deskriptif adalah penelitian yang tidak membuat perbandingan variabel itu pada sampel lain dan mencari hubungan variabel itu dengan variabel yang lain (Sugiyono,2008:35).
Penelitian ini dilakukan pada bulan Februari tahun 2019 di Fkip dengan responden merupakan mahasiswa PG-PAUD semester III. Populasi penelitian ini mencakup mahasiswa semester III PG-PAUD berjumlah 12 Orang kelas A dan dan kelas B berjumlah 14 orang.

Sampel merupakan perwakilan dari populasi.Sesuai dengan pendapat A. Muri Yusuf (2005:186) menyatakan bahwa sampel adalah sebagian dari populasi yang terpilih dan mewakili populasi tersebut.Pengambilan sampel dalam penelitian ini dilakukan dengan teknik Total Sampling. Keseluruhan populasi merupakan sampel pada penelitian ini.

Untuk melihat bagaimana pemahaman mahasiswa tentang aplikasi blanded learning peneliti membuat empat kategori yang akan memperjelas bagaimana pemahaman mahasiswa tentang blanded learning menggunakan rumus interval menurut Hadi (2006:178) yakni :

$$
\begin{aligned}
& I=\frac{N T-N R}{K} \\
& I=\frac{100-0}{4}=25 \\
& \text { Keterangan : } \\
& \text { I = Interval } \\
& \text { NT = Nilai Tertinggi } \\
& \text { NR = Nilai Terendah } \\
& \text { K= Kategori }
\end{aligned}
$$

Tabel berikut merupakan tabel kategori yang menjadi acuan untuk mendeskripsikan pemahaman mahasiswa tentang aplikasi blanded learning dalam proses perkuliahan. Terdapat empat kategori pemahaman yaitu tidak paham, belum paham, paham dan sangat paham.

\section{HASIL PENELITIAN DAN PEMBAHASAN}

Dari hasil penelelitian pemahaman mahasiswa menggunakan aplikasi blanded learning, terlihat bahwa mayoritas mahasiswa sudah paham menggunakan blanded learning dalam perkuliahan. Namun masih ada beberapa indikator yang belum dipahami oleh mahasiswa. Untuk indikator membuat akun blended learning diperoleh persentase sebesar 55,00 dengan kategori paham; untuk indikator mengakses masuk ke akun blended learning diperoleh persentase sebesar 68,00 dengan kategori paham; untuk indikator penguasaan metode menggunakan blended learning 
diperoleh persentase sebesar 48,45 dengan kategori paham; untuk indikator efektivitas penggunaan blended learning diperoleh persentase sebesar 68,70 dengan kategori sangat paham; untuk indikator Penguasaan materi penggunaan blanded learning diperoleh persentase sebesar 78,10 dengan kategori sangat paham; untuk indikator keaktifan mahasiswa dalam pembelajaran blanded learning diperoleh persentase sebesar 75 dengan kategori paham.

Berdasarkan hasil pengolahan data yang telah dilakukan didapat hasil sebagai berikut:

Tabel 5.1. Rekapitulasi Pemahaman Mahasiswa Terhadap kemampuan menggunakan aplikasi blended learning.

\begin{tabular}{|c|c|c|c|}
\hline No. & Indikator & Persentase & Kategori \\
\hline 1 & $\begin{array}{l}\text { Membuat } \\
\text { akun blended } \\
\text { learning }\end{array}$ & 55,00 & Paham \\
\hline 2 & $\begin{array}{l}\text { Mengakses } \\
\text { masuk ke } \\
\text { akun blended } \\
\text { learning }\end{array}$ & 68,00 & Paham \\
\hline 3 & $\begin{array}{l}\text { Penguasaan } \\
\text { Metode } \\
\text { menggunakan } \\
\text { blended } \\
\text { learning }\end{array}$ & 48,45 & $\begin{array}{l}\text { Belum } \\
\text { Paham }\end{array}$ \\
\hline 4 & $\begin{array}{l}\text { Efektivitas } \\
\text { penggunaan } \\
\text { blended } \\
\text { learning }\end{array}$ & 68,70 & Paham \\
\hline 5 & $\begin{array}{l}\text { Penguasaan } \\
\text { materi } \\
\text { penggunaan } \\
\text { blanded } \\
\text { learning }\end{array}$ & 78,10 & $\begin{array}{l}\text { Sangat } \\
\text { Paham }\end{array}$ \\
\hline 6 & $\begin{array}{l}\text { Keaktifan } \\
\text { mahasiswa } \\
\text { dalam } \\
\text { pembelajaran } \\
\text { blanded } \\
\text { learning }\end{array}$ & 75,00 & Paham \\
\hline
\end{tabular}

\section{Pembahasan}

Pada penelitian ini aspek yang dinilai yaitu pemahaman mahasiswa terhadap kemampuan menggunakan aplikasi blended learning. Indikator pertama yang dinilai yaitu membuat akun blanded learning pemahaman mahasiswa sudah masuk ke kategori paham dengan skor 55,00 dan mampu dalam mengaplikasikan blanded learning. Indikator kedua yaitu mahasiswa mampu mengakses masuk ke dalam akun blanded learning dengan skor 68,00 dengan kategori paham. Yang ketiga penguasaan mahasiswa pada metode yang menggunakan aplikasi blanded learning mahasiswa masih belum menguasai metode dengan menggunakan fitur blanded learning dengan skor 48,45 dengan kategori belum paham. Blended learning adalah program pengiriman yang memanfaatkan lebih dari satu metode untuk memberikan informasi kepada pelajar (Garrison \&kanuka dalam Shroff et al,2010). Didalam aplikasi blanded learning terdapat beberapa metode yang bebas dipilih oleh pendidik untuk digunakan dalam pembelajaran. Ada menggunakan link, google classroom, metode chatting, dan memasukkan dokumen secara manual.

Indikator yang keempat adalah efektifitas menggunakan blanded learning dimana aplikasi tersebut dapat digunakan ketika tatap muka maupun tidak bertatap muka. Keefektifan dalam menggunakan aplikasi tersebut oleh mahasiswa dengan skor nilai 68,70 kategori paham. Mahasiswa dapat menggunakan secara efektif pada pembelajaran tatap muka maupun jarak jauh. Sejalan dengan pendapat Colis \& Moonen (2001) mengemukakan bahwa model blended learning adalah campuran dari pembelajaran tatap muka dan pembelajaran online, sehingga memungkinkan pembelajaran tidak hanya terjadi di kelas saja namun juga dapat dilakukan di luar kelas. Kemudian indikator yang ke lima yaitu penguasaan materi penggunaan blanded learning dengan skor 78,10 yaitu dengan kategori sangat paham. Mahasiswa mudah menguasai materi dengan menggunakan aplikasi ini sesuai dengan kreativitas guru dalam menggunakan metode yang digunakan sehingga pendidik harus menggunakan metode yang mudah sehingga mahasiswa lebih mengerti dalam menguasai materi yang diberikan. Indikator terakhir yaitu keatifan mahasiswa dalam menggunakan aplikasi blanded learning dengan skor 75,00 kategori paham. Mahasiswa lebih aktif dalam menggunakan aplikasi blanded learning. Mahasiswa lebih mudah menyampaikan pendapat tanpa rasa malu karena mahasiswa ketika berdiskusi bebas menyampaikan 
pendapat tanpa harus disebutkan terlebih dahulu atau ditunjuk sehingga mahasiswa lebih aktif.

\section{SIMPULAN}

Berdasarkan hasil penelitian dan pembahasan dapat disimpulkan bahwa mahasiswa paham dalam mengaplikasikan blanded learning sehingga aplikasi ini dapat digunakan ketika berada dikelas maupun jarak jauh. Selain itu aplikasi ini sangat efektif ketika terjadi pandemi maupun bencana lainnya sehingga tidak memungkinkan untuk pembelajaran dikelas. Mahasiswa diawal pembelajaran sudah diwajibkan mempunyai akun dan wajib membuat akun sendiri sehingga mahasiswa paham dalam memnuat akaun dan mengakses masuk ke aplikasi. Sedangkan pada penggusaan metode mahasiswa beberapa belum paham karena aplikasi blanded learning mempunyai bermacam metode sehingga pendidik dapat memilih metode yang dapat dikuasai mahasiswa. Selain itu aplikasi ini efektif digunakan dan mahasiswa memahami serta lebih aktif dalam menggunakan fitur ini dalam pembelajaran. Dengan menggunakan fitur blanded learning mahasiswa lebih memahami materi yang diberikan oleh dosen sehingga mahasiswa dinilai dikategori sangat paham

\section{DAFTAR PUSTAKA}

Collis, B., \& Moonen, J. 2001. Flexible learning in a digital world. London: Kogan Page. distance learning: A technology perspective. International Journal of Instructional Technology and Distance Learning. 8(1):37-48. Tersedia pada http://www. itdl.org/Journal/jan_11/Jan_11.pdf.

Graham, C. R. 2006. Blended learning systems. In C. J. Bonk \& C. R. Graham, The handbook of blended learning: Global perspectives, local designs. Pfeiffer.

Grant Ramsay. 2001. Teaching and Learning With Information and Communication Technology: Succes Through a Whole School Approach. National Educational Computing Conference, July 25-27. Chicago.

Luik, P. 2006. Web based-learning or face-to-face teaching.Preferences of Estonian Students. Tersedia pada www.aare.edu.au/06pap/lui06159.pdf
Marczyk, G., DeMatteo, D., \& Festinger, D. 2005. Essentials of research design and methodology. New Jersey: John Wiley \& Sons.

Sahin, M. 2010. Blended learning in vocational education: An experimental study. International $\mathrm{Jl}$ of Vocational Education, 2(6), 95-101.Tersedia pada http: $\quad / / w w w . \quad$ Academic journals.org/ijvte $\quad / \mathrm{PDF} / \mathrm{pdf}$ 2010/October/Sahin.pdf.

Shroff, R.,Vogel,D. 2010. An investigation on individual students' perceptions of interest utilizing a Blended learning approach. International Jl. on ELearning 9(2):279-294. Tersedia pada http://edlab.tc.columbia.edu/files/ 29282.pdf

So, H.-J., \& Bonk, C. J. 2010. Examining the roles of blended learning approaches in computer-supported collaborative learning (CSCL) environments: A delphi study. Educational Technology \& Society, 13(3),189-200. Tersedia pada http:// www.ifets. info/journals/13_3/17.pdf.

Uzun, A., Senturk, A. 2010. Blending makes the difference: Comparison of blended and traditional instruction on students' performance and attitudes in computer literacy. Contemporary Educational Technology,1(3), 196-207. Tersedia pada http://cedtech. net/articles/131.pdf.

Yaman, M., Graf, D. 2010.Evaluation of an international blended learning cooperation project in biology teacher education. TOJET: The Turkish Online Journal of Educational Technology, 9(2) 89-96. Tersedia pada http :// www. tojet. net/articles /9210. pdf

Yuen, H, K. 2011. Exploring teaching approaches in blended learning. Research and Practice in Technology Enhanced Learning 6(1),3-23. Tersedia pada http: // apsce. net / RPTEL /RPTEL 2011 MarIssue- Article1_(p3-p23)R1.pdf.

Zuvic, M., Roncevic, N., Nemcanin, D. 2011. Blended e-learning in higher education: Research on students' perspective. Issues in Informing Science and Information Technology.4(8), 410-428. Tersedia pada iisit.org/Vol8 /IISITv8p409-429 Zuvic 247. pdf. 